\title{
The Structured Oral Examination in Clinical Anesthesia
}

\author{
Cyprian Mendonca, Carl Hillermann, Josephine James, Anil Kumar. TFM Publishing \\ Limited, UK, 2009, 558 pp, US\$70. ISBN 9781903378687
}

\author{
Susan O'Leary, MD
}

Published online: 26 September 2009

(C) Canadian Anesthesiologists' Society 2009

This book is designed as a study guide for trainees or residents preparing for their postgraduate examinations in anesthesia. The book addresses the areas of clinical knowledge, clinical skills, technical skills, problem solving, organization, and planning relevant to the specialty of anesthesia. The intent of the authors is to enable the trainee to identify her/his strengths and weaknesses in each of these areas. Written and published in the United Kingdom, three of the four authors are consultant anesthetists and the fourth is a specialist registrar.

The book is divided into ten sections, each consisting of structured questions in clinical anesthesia and clinical science. The clinical anesthesia questions are presented as one comprehensive case and three brief cases. The clinical science questions cover four topics: applied anatomy, physiology, pharmacology, and clinical measurement. Each section is representative of an examination paper written by the trainee in the United Kingdom.

This book's format for examination preparation differs from that of the Royal College of Physicians and Surgeons of Canada specialty examination in anesthesia. However, the book's content makes it a useful study guide for specialty examination preparation regardless of the country of certification. The topics cover current and clinically relevant information, for example, one lengthy clinical anesthesia issue is, "Perioperative Myocardial Infarction in a Patient Scheduled for a Hip Hemi-arthroplasty". The case description, which includes results of laboratory investigations, an electrocardiogram, and chest $x$-ray reproductions, is followed by a series of questions and answers regarding evaluation, interpretation of findings, and management.

S. O'Leary, MD ( $\square)$

Memorial University of Newfoundland, St. John's, NL, Canada

e-mail: soleary@nl.rogers.com
The brief cases are similarly structured with questions for each case based on a given scenario rather than following a specific template. However, the approach is a practical one. The questions require substantive answers that call for the interpretation of investigations, the generation of a differential diagnosis, or the management of medications.

This text incorporates the scientific aspects of anesthesia into practice. The clinical science scenarios focus on anatomy, pharmacology, physiology, or clinical measurement and these basic science concepts are applied to patient management. Applied anatomy may entail the discussion of pain pathways while clinical measurements may include capnometry. The 40 clinical science questions are brief clinically relevant discussions of topics not usually addressed by the standard oral examination question.

The format of this book makes it easy to read. One scenario can be read in less than twenty minutes, which makes the book useful for a quick review by the busy student. The chest $x$-rays, diagrams, electrocardiograms, and tables are well reproduced. Explanations do not accompany these items, but rather, they are incorporated into the answers to the questions. The index is thorough as is the list of abbreviations.

This book would be a useful study and reference guide for those preparing for the anesthesia Fellowship examinations. Likewise, anesthesiologists who prepare practice oral examination questions could adapt the questions in this book for that purpose. Reading this book would be enjoyable and educational for any anesthesiologist interested in a review of clinical problem solving. 